\title{
Effect of suppression of pituitary-testicular function during fetal life with a GnRH agonist on reproductive development in ram lambs during the first 28 weeks of life
}

\author{
G. B. Thomas*, A. S. McNeilly and A. N. Brooks \\ MRC Reproductive Biology Unit, Centre for Reproductive Biology, 37 Chalmers Street, \\ Edinburgh, EH3 $9 E W$, UK
}

\section{Introduction}

Over the past 50 years, total numbers of spermatozoa in man has declined by approximately $50 \%$ (Carlsen et al., 1992). One explanation for this decrease is that factors that affect the development of the fetal reproductive system may limit reproductive function in adults (Sharpe, 1993). We have demonstrated that suppression of fetal gonadotrophin secretion during the last half of gestation with a GnRH agonist results in a $40-45 \%$ reduction in the number of Sertoli cells and testicular size at birth (Thomas et al, 1994). Thus we have a model whereby we can manipulate the reproductive system during fetal life and study the consequences of such an intervention in later life. The aim of the present study, therefore, was to investigate whether impairment of gonadotrophic drive during fetal life influenced testicular size and function in neonatal sheep.

\section{Materials and Methods}

Mature pregnant Scottish Blackface ewes with known single insemination dates were used for the study. On day 75 of gestation (term $=145$ days), a biodegradable implant containing $3.0 \mathrm{mg}$ of the GnRH agonist, buserelin $\left[\mathrm{D}-\mathrm{Ser}(\mathrm{EBu})^{6}\right.$, Pro $\left.-\mathrm{NHEt}\right]-\mathrm{GnRH}_{1-9}$ (Hoechst AG, Frankfurt) was placed s.c. into the tail of 12 male fetuses (Brooks and McNeilly, 1992). Sham operations were performed in an additional 12 male fetuses (controls).

On the day after birth, the lambs received a bolus i.v. injection of $500 \mathrm{ng} \mathrm{GnRH}$. Blood samples were collected by venepuncture at $-15,0,5,20,40,60$ and 90 min relative to injection for $\mathrm{LH}$ and testosterone assay. The implant was then removed by docking the tail and blood samples collected twice weekly for 28 weeks for LH, FSH and inhibin assay. The GnRH treatment was repeated at $2,4,6,8,10$, $12,16,20$ and 28 weeks of age, when the lambs were also weighed and the testicular diameter measured using callipers. The concentrations of LH, FSH, testosterone (Baird $\mathrm{et}$ al., 1981) and immunoreactive inhibin (McNeilly et al., 1989) were measured by previously described radioimmunoassays.

The influence of buserelin was analysed by a two-way analysis of variance using a repeated measures design. When a significant $(P<0.05)$ treatment effect was found, a Duncan's multiple-range test was used to test for significant differences between individual means.

\section{Results}

Treatment with buserelin from day 75 of gestation until birth resulted in a significant $(P<0.05)$ reduction in the diameter of the testes at birth and in the first 8 weeks of life compared with control ram 
lambs (Fig. 1a). By 10-12 weeks of age, however, mean testis diameter was similar in both groups. Mean plasma concentrations of FSH in GnRH agonist pretreated lambs were significantly $(P<0.05)$ higher between 3 and 8 weeks of age compared with controls (Fig. 1b). Treatment with buserelin had no effect on plasma concentrations of immunoreactive inhibin (Fig. Ic) or LH (data not shown). Lamb birth masses (control, $4.3 \pm 0.2 \mathrm{~kg}$ versus buserelin, $4.6 \pm 0.3 \mathrm{~kg}$ ) and growth rates (controls, $1.23 \pm 0.03 \mathrm{~kg}$ week $^{-1}$ versus buserelin, $1.22 \pm 0.07 \mathrm{~kg}$ wee $^{-1}$ ) were similar between groups.

At birth, injection of $500 \mathrm{ng} \mathrm{GnRH}$ elicited an immediate increase in $\mathrm{LH}$ secretion in all control lambs (Fig. 2). Plasma testosterone concentrations subsequently increased $40-90 \mathrm{~min}$ later (Fig. 2). These responses were completely abolished in newborn lambs treated with buserelin during the last half of gestation. After removal of the buserelin implant, the magnitude of the LH response remained significantly $(P<0.01)$ lower in GnRH agonist pretreated lambs between 2 and 12 weeks of age compared with controls. However, in both groups, there was a progressive increase between 2 and 8 weeks of age in the magnitude of the LH response to $\mathrm{GnRH}$ injection (Fig. 2). Between 16 and 28 weeks of age, there was no significant difference between the two groups in the amplitude of the LH response to $\mathrm{GnRH}$ administration; the size of the response decreased with age in both groups.

Despite the reduced LH response between 2 and 12 weeks of age in lambs pretreated with GnRH agonist, both groups exhibited similar testosterone responses to the GnRH-induced LH release (Fig. 2). In both groups, the plasma testosterone concentrations progressively increased between 2 and 20 weeks of age. At 28 weeks of age, following puberty, there was a two- to threefold increase $(P<0.01)$ in plasma testosterone concentrations, with control lambs having significantly $(P<0.01)$ higher concentrations of testosterone compared with buserelin pretreated lambs (Fig. 2).

\section{Discussion}

The present data show that administration of a GnRH agonist during the last half of gestation results in a transient decrease in testicular size during the first 8 weeks of life. Furthermore, the compensatory growth of the testis in newborn lambs after GnRH agonist removal was associated with increased plasma concentrations of FSH. Since the regulation of numbers of Sertoli cells is a major determinant of testicular size (Berndtson et al., 1987) and replication of Sertoli cells during fetal and neonatal life is predominantly under FSH control (Mann et al, 1989), it is likely that the increased rate of testicular growth observed following GnRH agonist pretreatment reflects an increase in Sertoli cell proliferation in response to increased concentrations of FSH. This is analogous to the situation following unilateral castration in prepubertal lambs, whereby compensatory hypertrophy of the remaining testis is accompanied by high concentrations of FSH and blockade of this increase prevents compensatory testicular growth (Jenkins and Waites, 1983).

The increase in FSH concentrations between 3 and 8 weeks of life in GnRH agonist pretreated lambs is likely to result from a reduction in the negative feedback by testicular factors. Although immunoreactive inhibin concentrations were similar in $\mathrm{GnRH}$ agonist pretreated and control lambs, a reduction in negative feedback by inhibin cannot be excluded entirely, since our assay detects forms of inhibin other than dimeric inhibin. This may obscure any decrease in feedback by dimeric inhibin. Another possibility is that a reduction in testicular steroids, in particular oestrogens of Sertoli cell origin, may be responsible for the increase in FSH secretion. Support for this hypothesis is provided by several observations. First, it is well established that immature Sertoli cells are a source of oestrogen during prepubertal development (see Sharpe, 1994 for review). Second, we have shown that reduced gonadotrophic support during the last half of gestation results in a reduction in the number of Sertoli cells at birth (Thomas et al., 1994). Finally, immunization of ram lambs against oestradiol or oestrone results in an increase in plasma FSH concentrations that is associated with an increase in testicular growth (Land et al., 1981).

The finding that GnRH agonist pretreated lambs secreted a similar amount of testosterone despite having reduced testicular size and an attenuated $\mathrm{LH}$ response to $\mathrm{GnRH}$ stimulation was surprising. However, there is considerable evidence that Sertoli cells, under FSH control, can act to modulate Leydig cell differentiation and function during prepubertal development (see Sharpe, 1994 for review). Thus, the 

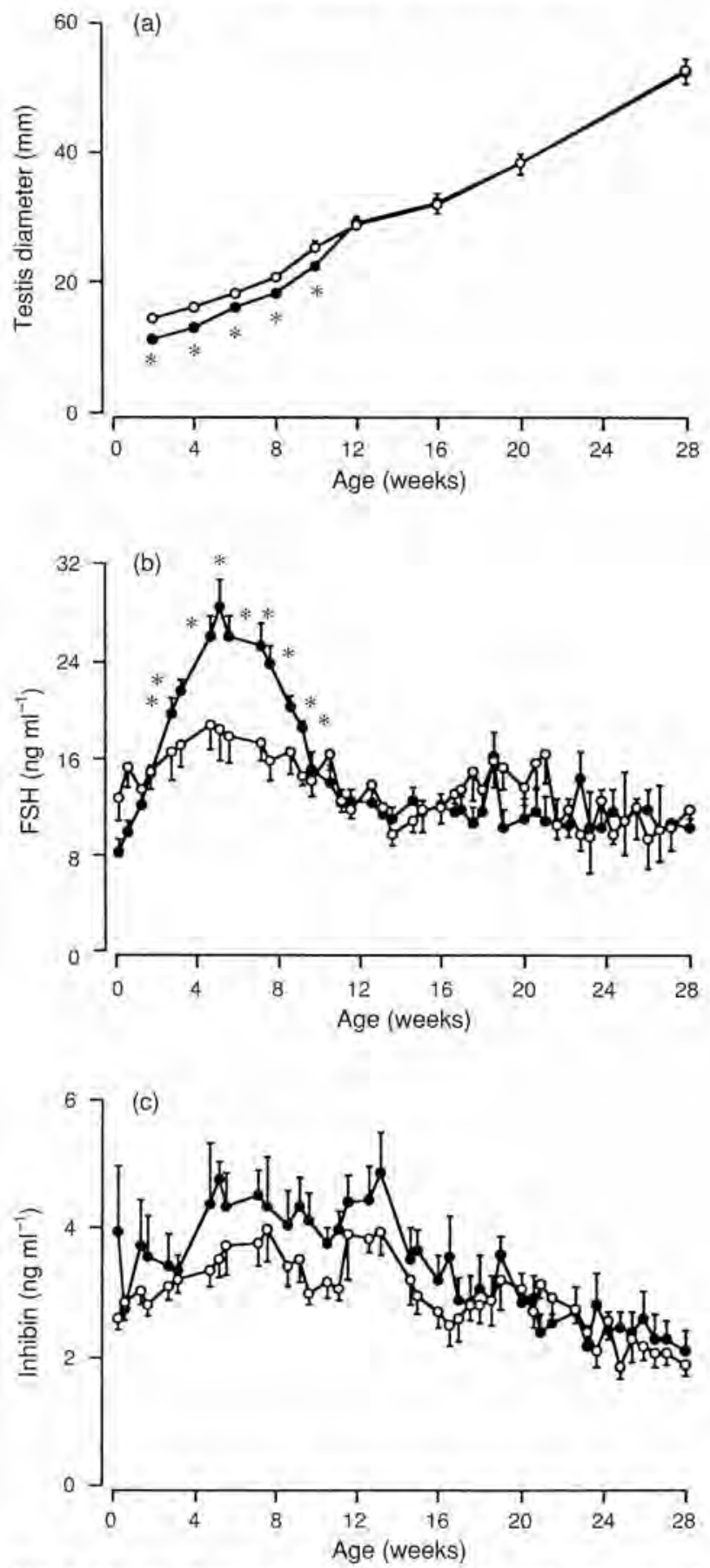

Fig. 1. Changes during the first 28 weeks of life in (a) diameter of the testis; and plasma concentrations of (b) FSH and (c) immunoreactive inhibin in control lambs (o) and lambs implanted from day 75 of gestation until birth with $3.0 \mathrm{mg}$ buserelin ( $\bullet$ ). Values are means \pm SEM of $I 2$ animals per group. ${ }^{*} P<0.05$ compared with control. 

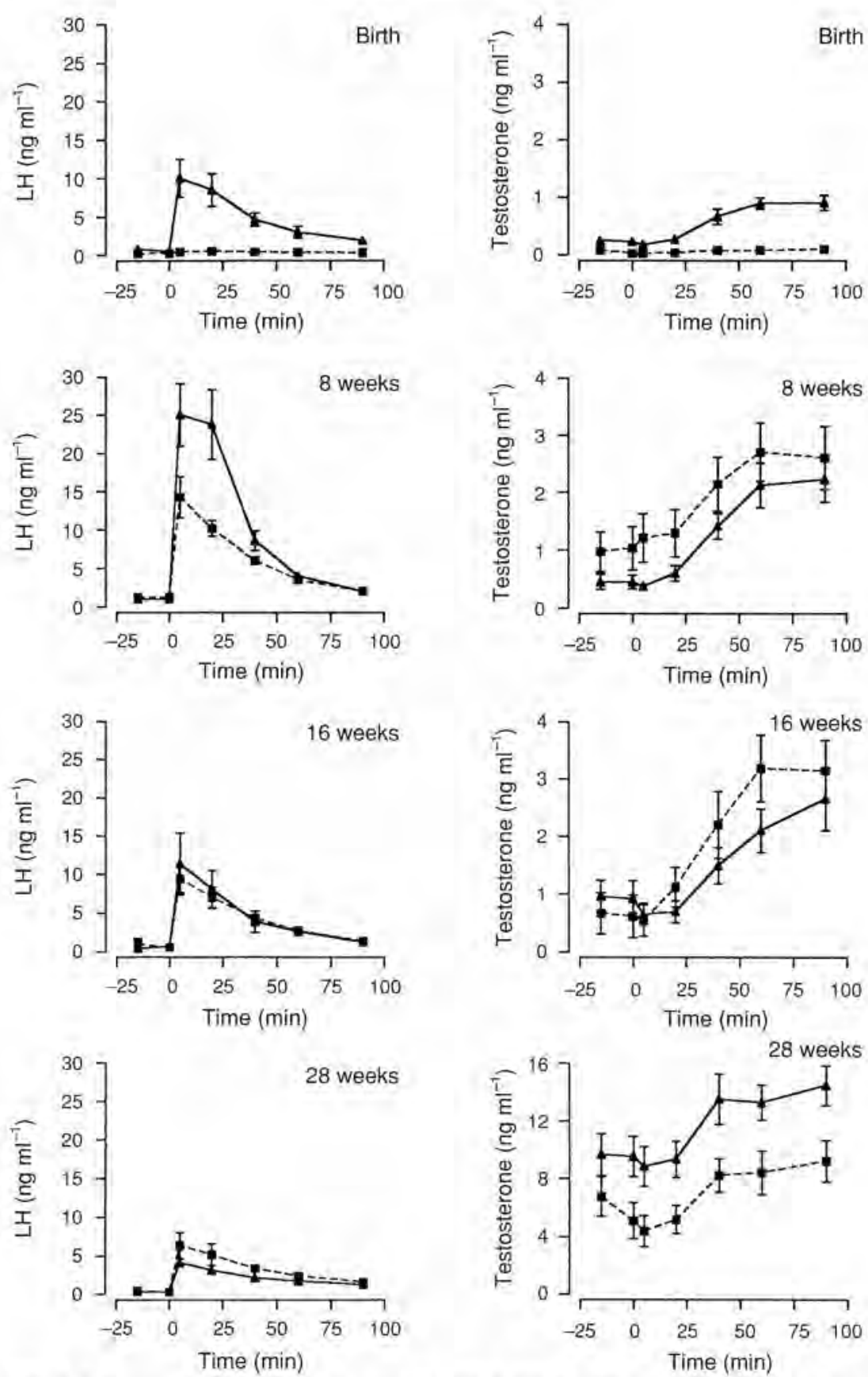

Fig. 2. Changes during the first 28 weeks of life in the plasma concentration of LH and testosterone in response to a $500 \mathrm{ng}$ i.v. injection (time 0) of GnRH in control lambs (4) and lambs implanted from day 75 of gestation until birth with $3.0 \mathrm{mg}$ buserelin (-). Values are means \pm SPM of 12 animals per group.

increase in FSH concentrations in $\mathrm{GnRH}$ agonist pretreated lambs may have caused an increase in the sensitivity of the Leydig cells to respond to stimulation by $\mathrm{LH}$. For example, treatment of hypophysectomized immature rats with FSH has been shown to increase the number of testicular LH 
receptors, resulting in an increase in capacity of the Leydig cells to secrete testosterone in response to LH (Selin et al, 1977).

By 28 weeks of life, after the animals had attained puberty, plasma testosterone concentrations were significantly higher in control lambs than in lambs pretreated with $\mathrm{GnRH}$ agonist during the later stages of fetal development. This finding suggests that, although the testes of $\mathrm{GnRH}$ agonist pretreated lambs appear to have undergone complete compensatory growth in the prepubertal period, there may be important functional aspects which remain impaired. If these defects were to be still apparent during the rest of adult life, the result could be impaired reproductive function (for example, spermatogenesis) and behaviour. In conclusion, the present study supports the contention that impaired gonadotrophic drive during fetal life may influence reproductive potential in adult life. This issue should be addressed with priority in future studies.

The authors thank N. Anderson, 1. Cooper, J. Docherty, V. Grant, F. Pitt, W. Struthers and I. Swanston for expert technical assistance; R. M. Sharpe for helpful discussion and comments, and R. Humke (Hoechst AG, Frankfurt, Germany) for the generous gift of buserelin implants. Reagents for the gonadotrophin radioimmunoassays were generously supplied by the National Hormone and Pituitary Program, Rockville. MD.

\section{References}

Baird DT. Swanston IA and McNeilly AS (1981) Relationship between $\mathrm{LH}, \mathrm{FSH}$, and prolactin concentrations and the secretion of androgens and estrogens by the preovulatory follicle in the ewe Biology of Reproduction $241013-1025$

Berndtson WE, lgboeli G and Parker WG (1987) The numbers of Sertoli cells in mature Holstein bulls and their relationship to quantitative aspects of spermatogenesis Biology of Reproduction 37 60-67

Brooks AN and McNeilly AS (1992) Inhibitory effects of a luteinizing-hormone-releasing hormone agonist implant on ovine fetal gonadotrophin secretion and pituitary sensitivity to luteinizing-hormone-releasing hormone Joumal of Reproduction and Ferfility 96 785-792

Carlsen E, Giwercman A, Keiding N and Skakkeback NE (1992) Evidence for decreasing quality of semen during past 50 years British Medical Joumal $305609-613$

Jenkins $\mathrm{N}$ and Waites GMH (1983) Effects of hemicastration at various ages and of oestradiol-17B on plasma concentrations of gonadotrophins and androgens, testicular growth and interstitial cell responses in prepubertal lambs Journal of Reproduction and Ferlitity 67 325-334

Land RB, Baird DT and Carr WR (1981) Increased testicular growth of Tasmanian Merino ram lambs treated with antisera to oestrogens Journal of Reproduction and Fertility 62 151-158
McNeilly AS, Swanston IA, Crow W, Tsonis CG and Baird DT (1989) Changes in plasma concentration of inhibin throughout the normal sheep oestrous cycle and after infusion of FSH Journal of Endocrinology $\mathbf{1 2 0}$ 295-305

Mann DR, Gould KG, Collins DC and Wallen K (1989) Blockade of neonatal activation of the pituitary-testicular axis: effect on peripubertal $\mathrm{LH}$ and testosterone secretion and on testicular development in male monkeys Joumal of Clinical Endocrinology and Metabolism 68 600-607

Selin LK and Moger WH (1977) The effect of FSH on LH induced testosterone secretion in the immature hypophy. sectomized male rat Endocrine Research Communicafions 4 $171-182$

Sharpe RM (1993) Declining sperm counts in men - is there an endocrine cause? Joumal of Endocrinology 136 357-360

Sharpe RM (1994) Regulation of spermatogenesis. In The Physiology of Reproduction pp 1363-1434 Eds E Knobil and ID Neill. Raven Press, New York

Thomas GB, McNeilly AS, Gibson F and Brooks AN (1994) Effects of pituitary-gonadal suppression with a gonadotrophin-releasing hormone agonist on fetal gonadotrophin secretion, fetal gonadal development and maternal steroid secretion in the sheep Journal of Endocrinology $\mathbf{1 4 1}$ $317-324$ 